\title{
Transcriptional regulation of the Escherichia coli rhat gene
}

\author{
Pilar Vía, Josefa Badía, Laura Baldomà, Nuria Obradors and Juan Aguilar
}

Author for correspondence: Juan Aguilar. Tel: +34 3402 4521. Fax: +34 34021896.

e-mail: Jaguilar@far.ub.es

Department of Biochemistry, Faculty of Pharmacy, University of Barcelona, Diagonal 643, 08028 Barcelona, Spain

\begin{abstract}
Transcriptional regulation of the rhat gene, one of the operons forming the rhamnose regulon in Escherichia coli, was studied by fusing its complete or deleted promoter to the reporter gene lacz. Analysis of $\beta$-galactosidase activities induced in these constructions grown under different conditions predicted the presence of two putative control elements: one for the RhaS regulatory protein and activating the gene not only by L-rhamnose but also by L-lyxose or L-mannose, the other for CAMP-catabolite repression protein and activating this gene in the absence of glucose. Anaerobiosis increased the promoter function two- to threefold with respect to the aerobic condition. Experiments involving complementation of strains containing the rhatpromoter fusion and carrying a deletion in the rhaS and/or rhaR genes with plasmids bearing the rhamnose regulatory genes showed that rhat is controlled by a regulatory cascade, in which RhaR induces rhaSR and the accumulated Rhas directly activates rhar.
\end{abstract}

Keywords: rhamnose transport, rhaT, regulation, transcription, Escherichia coli

\section{INTRODUCTION}

L-Rhamnose is metabolized in Escherichia coli by a set of catabolic enzymes encoded by the genes of the rhamnose regulon, which is composed of two operons. One, $r b a B A D$, encodes thamnulose kinase $(r b a B)$, rhamnose isomerase $(r b a A)$ and rhamnulose-1-phosphate aldolase (rbaD) (Badía et al., 1989; Power, 1967). The other, rbaT, encodes the rhamnose transport system (Baldomà et al., 1990). The rhamnose regulon is under the control of the regulatory locus rbaC (Power, 1967), containing two genes, rbaR and rbaS (Chen et al., 1987; Tobin \& Schleif, 1987). The complete thamnose system has been cloned and sequenced, and several of its putative regulatory sequences in the promoter and terminator fragments have been identified (García-Martín et al., 1992; Moralejo et al., 1993; Tate et al., 1992; Tobin \& Schleif, 1987). Rhamnose metabolism is under catabolite repression by glucose, which is overcome by the binding of cAMP-catabolite repression protein (CRP) to a consensus recognition sequence found in the promoter of $r b a B A D$ (Egan \& Schleif, 1993). The rhamnose regulon is also induced by the pentose L-lyxose (Badía et al., 1991), which is structurally similar to L-rhamnose and is metabolized by the

Abbreviations: CRP, catabolite repression protein; tsp, transcriptional start point. enzymes of the rhamnose pathway in mutants able to utilize this pentose. Tobin \& Schleif (1990a) found that $\mathrm{RhaR}$ protein directly activates rhaSR transcription in response to L-rhamnose. Later, Egan \& Schleif (1993) showed that induction of $r b a B A D$ involves a regulatory cascade in which the induction of rbaSR results in the accumulation of RhaS, which in turn induces rbaB $A D$ expression. In this report we show that $r b a T$ is also under the RhaR-RhaS cascade for induction by L-rhamnose.

\section{METHODS}

Bacterial strains and growth conditions. The bacterial strains used in this study are listed in Table 1. Cells were grown aerobically or anaerobically as described previously (Boronat \& Aguilar, 1979) on Luria broth or minimal medium. For growth on minimal medium L-rhamnose, L-mannose, L-lyxose or Dglucose were added to a concentration of $10 \mathrm{mM}$ for aerobic conditions or $20 \mathrm{mM}$ for anaerobic conditions. Casein acid hydrolysate, used only in aerobic conditions, was prepared at $1 \%(\mathrm{w} / \mathrm{v})$. Where indicated, ampicillin was used at $100 \mu \mathrm{g} \mathrm{ml}^{-1}$, chloramphenicol at $20 \mu \mathrm{g} \mathrm{ml}^{-1}$, kanamycin at $30 \mu \mathrm{g} \mathrm{ml}^{-1}$, streptomycin at $25 \mu \mathrm{g} \mathrm{ml}^{-1}$ and thiamin at $20 \mu \mathrm{g} \mathrm{ml}^{-1}$.

DNA manipulation. Plasmid DNA was routinely prepared by the boiling method (Holmes \& Quigley, 1981). For large-scale preparation, a crude DNA sample was purified on a column (Qiagen). DNA manipulations were performed essentially as described by Sambrook et al. (1989). The DNA sequence was 
Table 1. E. coli strains

\begin{tabular}{|c|c|c|}
\hline Strain & Relevant genotype & Source or reference \\
\hline ECL1 & $\mathrm{HfrC}$ pho $A 8$ rel $A 1$ ton $A 22 \mathrm{~T} 2^{\mathrm{r}}$ (lambda) & Lin (1976) \\
\hline TE2680 & $\begin{array}{l}\mathrm{F}^{-} \lambda^{-} \mathrm{IN}(r r n D-r r n E) / \Delta(l a c) X 74 \text { rplS galK2 } \\
\text { recD }:: \operatorname{Tn} 10 d-\mathrm{Tet} \operatorname{trpDC} 700:: p u t P A 1303:: \\
{\left[\mathrm{Kan}^{\mathrm{s}} \mathrm{Cam}^{\mathrm{r}} \text { lac }\right]}\end{array}$ & Elliot (1992) \\
\hline GD246 & MC4100 glpF:: Tn10 $\Phi(g l p K:: l a c Z) p c n B \Delta r b s 7$ & Sweet et al. (1990) \\
\hline DF903 & $\Delta(r b a-p f k A) 15 p f k B 1$ & Daldal \& Fraenkel (1981) \\
\hline$\triangle \mathrm{RHA} 2$ & $\mathrm{~F}^{-} \Delta(r b a T-r b a \mathrm{R}) \Delta l a c U 169$ end $A$ bsd $\mathrm{R}$ thi & $\begin{array}{l}\text { E. C. C. Lin } \\
\text { (unpublished) }\end{array}$ \\
\hline CGSC4833 & thi-1 rbaC4 lacZ82 gal-33 & $\begin{array}{l}\text { B. Bachmann (Coli } \\
\text { Genetic Stock Center) }\end{array}$ \\
\hline JA140 & TE2680 (pRS550-PV1:: lacZ) & This study \\
\hline JA141 & TE2680 (pRS550-PV2::lacZ) & This study \\
\hline JA142 & TE2680 (pRS550-PV3:: lacZ) & This study \\
\hline JA143 & TE2680 (pRS550-PV4::lacZ) & This study \\
\hline JA144 & TE2680 (pRS550-PrbaB::lacZ) & This study \\
\hline JA145 & GD246 $\Delta(r b a-p f k A) 15$, but $g l p^{+}$ & This study \\
\hline JA146 & GD246 $\Delta(r b a T-r b a R)$, but $g l p^{+}$ & This study \\
\hline JA147 & JA145 (pRS550-PV1::lacZ) & This study \\
\hline JA148 & JA145 (pRS550-PrbaB:: lacZ) & This study \\
\hline JA149 & JA146 (pRS550-PV1::lacZ) & This study \\
\hline JA160 & JA146 (pRS550-PrbaB::lacZ) & This study \\
\hline
\end{tabular}

determined by the dideoxynucleotide chain-termination procedure of Sanger et al. (1977). Double-stranded plasmid DNA was used as the template.

RNA preparations and Northern-blot experiments. For preparation of total RNA, cells of a $25 \mathrm{ml}$ culture grown to $\mathrm{OD}_{650}$ 0.5 were collected by centrifugation at $5000 \mathrm{~g}$ for $10 \mathrm{~min}$ and processed as described by Belasco et al. (1985). Northern-blot hybridization was performed with each RNA sample $(10 \mu \mathrm{g})$, following the procedure described previously (Moralejo et al., 1993).

Primer extension analysis. This was performed by the procedure of $\mathrm{Hu} \&$ Davidson (1986), which involved hybridization of mRNA to a single-stranded DNA template and annealing of a radiolabelled DNA primer to the template at a site upstream from the $5^{\prime}$ end of the mRNA. Extension of the primer by T4 DNA polymerase should stop at the $5^{\prime}$ end of the hybridized mRNA; therefore, the $3^{\prime}$ end of the growing DNA chain marks its position. T4 DNA polymerase was purchased from Promega.

Construction of rhat promoter deletions and rhat-lacz fusions. Deletions were generated from plasmid pPV1 (Fig. 1) either by the Promega exonuclease III/S1 nuclease system or by restriction enzyme digestion. Restriction products that had $5^{\prime}$ or 3 ' overhanging ends were converted to blunt ends with Klenow fragment of $E$. coli DNA polymerase I, and cloned into Bluescript vector previously digested with $S \mathrm{maI}$. The resulting plasmids were sequenced and those with the desired fragments in the correct orientation were digested with EcoRI and Bam HI to be subcloned into the ampicillin and kanamycin resistance vector pRS550 (Simons et al., 1987).

Single-copy fusions on the $E$. coli chromosome were obtained by the method of Elliot (1992). Plasmids containing the different $r b a T-l a c Z$ fusions were linearized with $X b o I$, electrophoresed and purified by Gene-Clean. Strain TE2680 (Elliot, 1992) was transformed with $1 \cdot 0-2 \cdot 0 \mu \mathrm{g}$ of the linearized DNA. Due to the presence in strain TE2680 of the recD:: Tn10 mutation and sequences inserted into the trp operon that are homologous to sequences in the pRS plasmids, this strain recombines linear pRS550-based plasmids into its chromosome. The transformants were selected for kanamycin resistance and screened for sensitivity to ampicillin and chloramphenicol. P1vir lysates were made from the fusion strains and used to transduce the fusions into pcnB strains JA145 and JA146, which contained the rba deletions of strains DF903 and $\triangle$ RHA2, respectively. The $p c n B \Delta r b a$ mutants were obtained by P1 transduction of the rhamnose deletion into strain GD246 (Sweet et al., 1990), together with functional $g l p F$ and $g l p K$ genes. Transductants were selected for growth on glycerol and screened for the inability to utilize L-rhamnose.

Preparation of cell extracts and enzyme assays. For enzyme assay, the cells were harvested at the end of the exponential phase and the cell extract was prepared as described previously (Boronat \& Aguilar, 1979) with $10 \mathrm{mM}$ Tris/ $\mathrm{HCl}$ buffer, $\mathrm{pH} 7 \cdot 3$.

The $\beta$-galactosidase activity in strains grown under specified conditions was assayed as described by Miller (1972); the values are reported in $\mathrm{nmol} \mathrm{\textrm {min } ^ { - 1 }}(\mathrm{mg} \text { protein })^{-1}$. L-Rhamnose permease activity was determined by the rate of uptake of $\mathrm{L}^{-}$ $\left[{ }^{14} \mathrm{C}\right]$ rhamnose $\left[210 \mathrm{mCi} \mathrm{mmol}^{-1}\left(7 \cdot 7 \mathrm{GBq} \mathrm{mmol}^{-1}\right)\right.$; CEA, Gif sur Yvette, France] by whole cells. Cells were harvested and the assay was performed as described for fucose transport by Hacking \& Lin (1976), using a rhamnose concentration of $0.2 \mathrm{mM}\left[0.8 \mathrm{mCi} \mathrm{mmol}^{-1}\left(29.6 \mathrm{MBq} \mathrm{mmol}^{-1}\right)\right]$. Isomerase activity was determined as described by Takagi \& Sawada (1964), measuring ketose formation by the cysteine-carbazole method (Dische \& Borenfreund, 1951) with tagatose as a standard. One unit of isomerase activity was defined as the amount of enzyme that catalysed the formation of $1 \mu \mathrm{mol}$ ketose $\mathrm{min}^{-1}$ at $37^{\circ} \mathrm{C}$.

The protein concentration in cell extracts was determined by the Lowry method, with bovine serum albumin as standard. 


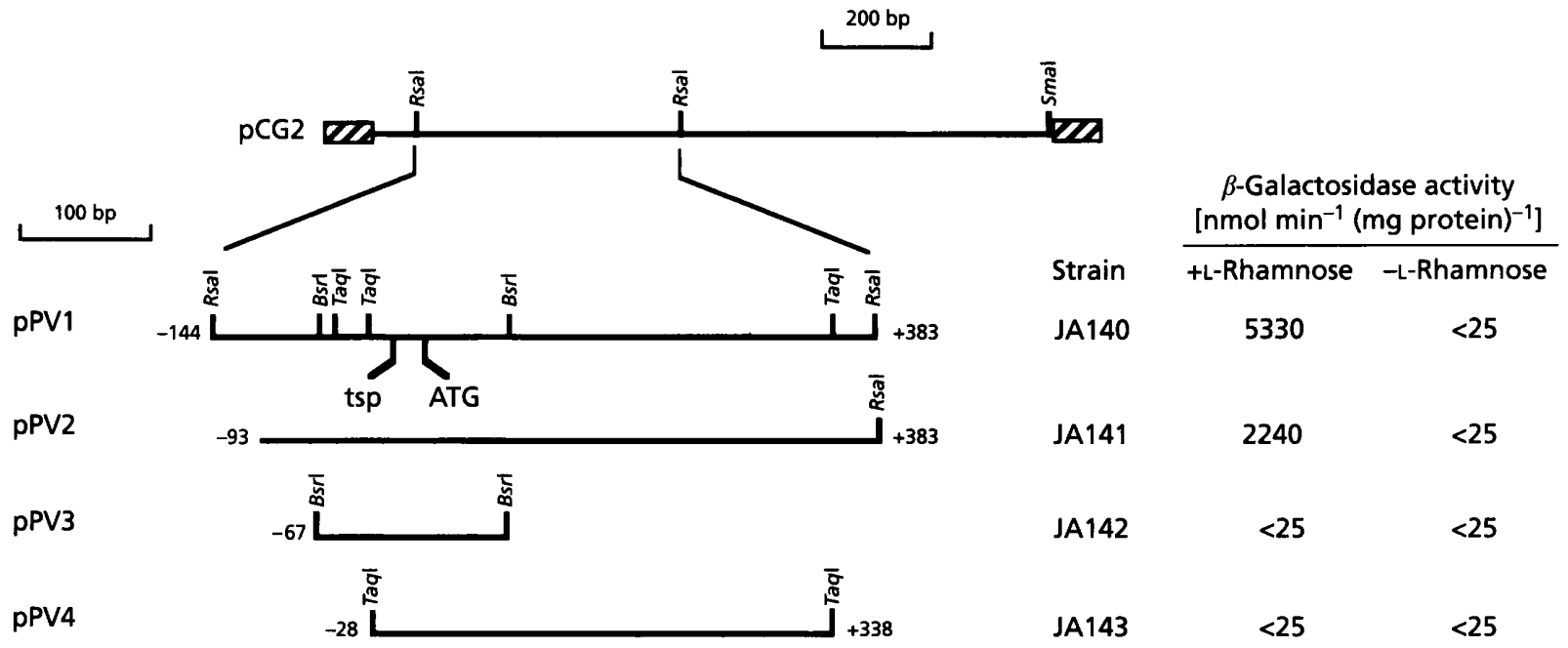

Fig. 1. Restriction map of plasmid inserts containing the rhaT promoter region and sequential deletions thereof, derived from recombinant Bluescript plasmid pCG2. Numbers indicate the terminal end positions of plasmid inserts. The hatched bar represents the Bluescript vector, which was used in all constructions. Tsp and the ATG initiating codon are indicated. Inserts, labelled on the left margin, were cloned into the pRS550 fusion vector, crossed onto the $E$. coli chromosome and assayed for $\beta$-galactosidase activity from cells grown on casein acid hydrolysate in the presence or in the absence of L-rhamnose.

\section{RESULTS}

\section{Transcription and transcriptional start site of the rhat gene}

Total RNA from cells of strain ECL1 grown under noninducing (casein acid hydrolysate) or inducing (casein acid hydrolysate plus rhamnose, or minimal medium with rhamnose) conditions was prepared as indicated above. Northern-blot hybridization performed with a probe of $420 \mathrm{bp}$ (Sau3A fragment from the rbaT open reading frame) showed a transcript of $1.1 \mathrm{~kb}$ in the RNA preparation obtained from induced cells, while no hybridization band was detected when RNA preparations of non-induced cells were used (Fig. 2).

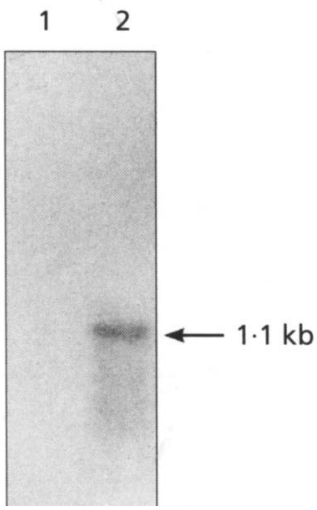

Fig. 2. Northern blots of total RNA from strain ECL1 grown aerobically on casein acid hydrolysate (lane 1), or casein acid hydrolysate plus rhamnose (lane 2). Hybridization was performed with a 420 bp Sau3A probe from the rhaT open reading frame.

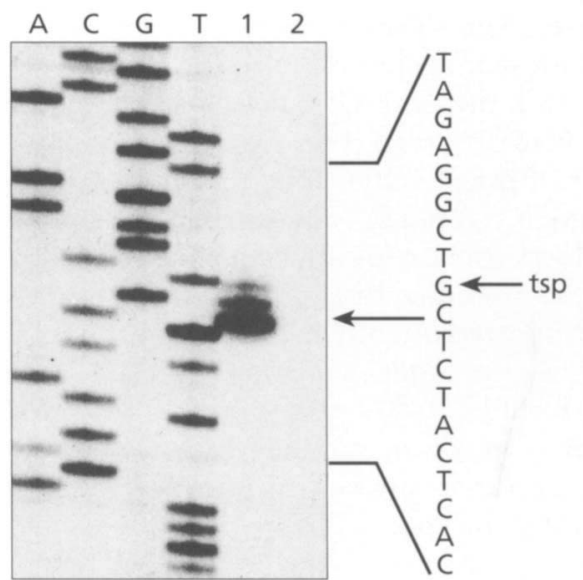

Fig. 3. Identification of the $5^{\prime}$ end of the rhaT transcript. The primer-extended products (lane 1) were electrophoresed with a sequencing ladder (lanes $A, C, G$ and $T$ ) generated by using the same template and primer. A control reaction without RNA was run in lane 2 . A portion of the nucleotide sequence deduced from the sequencing lanes is shown on the right. The most intense extended product is indicated by an arrow; it corresponds to a transcription initiated at the following $G$ nucleotide, labelled tsp.

The site of transcription initiation of the rhaT gene was determined by primer extension analysis. Total mRNA was prepared from strain ECL1 grown aerobically on Lrhamnose. The DNA template used in this experiment was derived from plasmid pCG2 (Fig. 1), a deletion obtained from plasmid pCG1 (García-Martín et al., 1992), with an insert containing the rbaT gene and $250 \mathrm{bp}$ upstream from the ATG codon. Single-stranded DNA of 
(a)

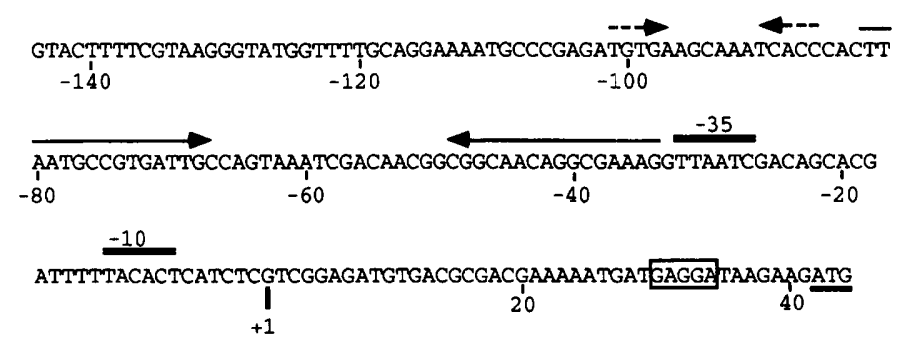

(b)

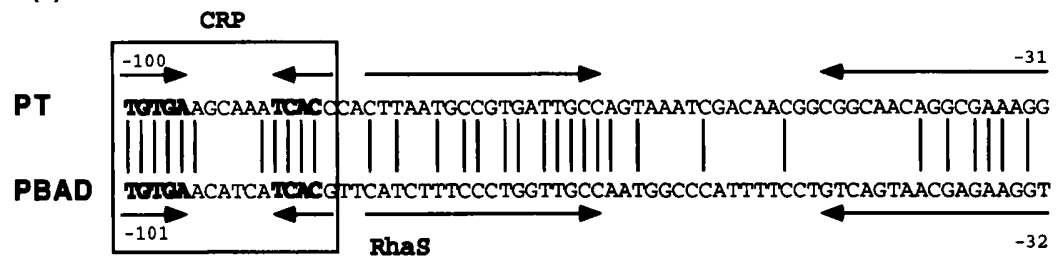

Fig. 4. (a) Nucleotide sequence of the Rsal-ATG fragment of plasmid PPV1 encompassing the promoter region of rhaT. Dashed arrows indicate the inverted repeat corresponding to the putative CRP binding site; solid arrows indicate the inverted repeat corresponding to the proposed Lrhamnose-specific regulator element. The transcription initiation nucleotide (position 1) and the -10 and -35 promoter sequences are indicated. The ribosomebinding site is boxed and the ATG initiation codon is underlined. (b) Alignment of rhaT (PT) and rhaBAD (PBAD) promoter sequences encompassing the two control elements, which are indicated by the arrows. Vertical lines mark identical nucleotides present in both fragments. The sequences recognized by CRP are boxed and conserved nucleotides in the CRP consensus (de Crombrugghe et al., 1984) are in outline (bolder) type. this template was hybridized with the total mRNA preparation. After annealing with ${ }^{32} \mathrm{P}$-labelled sequencing primer that was complementary to the Bluescript polylinker region, the primer was extended with T4 DNA polymerase. The samples were subjected to PAGE in parallel with sequencing mixtures prepared with the same template and primer. Three products differing in one basepair were observed (Fig. 3, lane 1) which were absent when the primer extension reaction was performed without mRNA (lane 2). The smallest and most intense of the products obtained after extension of the primer towards the $5^{\prime}$-end of the hybridized RNA allowed us to define the more frequently used transcriptional start point (tsp) (Fig. 3), the other two being used less often. The tsp was thus located at $40 \mathrm{bp}$ upstream from the ATG and was taken as position number 1 in the rbaT promoter sequence reported by García-Martin et al. (1992) and presented in Fig. 4(a).

\section{Transcriptional activation of the rhaT-lacz fusion}

The use of $\beta$-galactosidase activity as a reporter of the $r b a T$ promoter function allowed us to study the effect of different conditions on the expression of rbaT. For this purpose the merodiploid strain JA140, containing the fusion pRS550-PV1, in which fragment 1 contains the whole putative rbaT promoter (Fig. 1), was grown in the different conditions and $\beta$-galactosidase activity was measured in the corresponding extracts (Table 2). The gene was found to be induced not only by L-rhamnose or L-lyxose, as expected, but also by the structurally related sugar L-mannose. The $\beta$-galactosidase activities were of the same order for the three sugars and were routinely higher in the cells induced by L-mannose. Growth on glucose or glycerol, non-inducers of the rhamnose regulon, gave undetectable levels of activity (Table 2). In addition, growth in the presence of glucose was shown to produce catabolite repression in the function of the rbaT promoter. Experiments in which the time course of the
Table 2. $\beta$-Galactosidase activities in strains JA140 and JA141 grown under different conditions

\begin{tabular}{|lccc|}
\hline $\begin{array}{l}\text { Carbon } \\
\text { source }\end{array}$ & Oxygen & $\begin{array}{c}\boldsymbol{\beta} \text {-Galactosidase } \\
\text { activity } \\
\text { [nmol } \text { min }^{-1}\end{array}$ \\
& & & \multicolumn{2}{c|}{\begin{tabular}{cc} 
(mg protein $)^{-1}$ ] \\
\cline { 2 - 4 }
\end{tabular}} & & Strain & Strain \\
JA140 & JA141 \\
\hline L-Rhamnose & + & 5770 & 2430 \\
L-Rhamnose & - & 17500 & 6810 \\
L-Lyxose & + & 2660 & 1450 \\
L-Mannose & + & 5860 & 2705 \\
D-Glucose & + & $<25$ & $<25$ \\
Glycerol & + & $<25$ & $<25$ \\
\hline
\end{tabular}

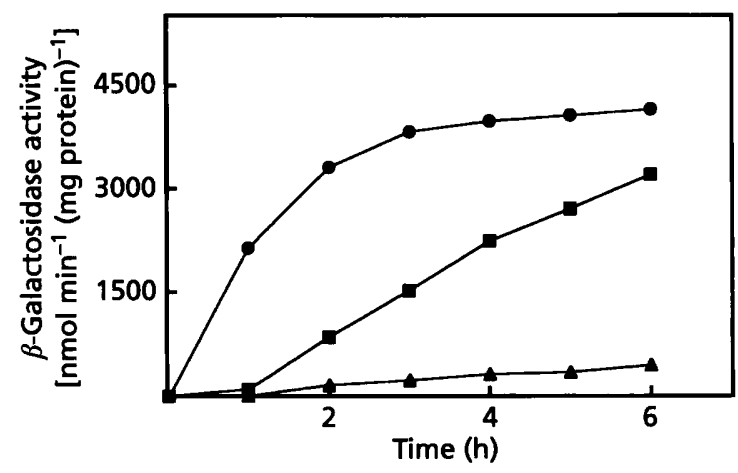

Fig. 5. Time course of $\beta$-galactosidase activity of strain JA140 grown aerobically on rhamnose $(0)$, rhamnose plus glucose $(A)$, or rhamnose plus glucose plus $5 \mathrm{mM}$ CAMP (a). A rhamnose-grown inoculum was used to start $200 \mathrm{ml}$ of each of the three cultures; $10 \mathrm{ml}$ samples were taken at $1 \mathrm{~h}$ intervals for determination of the $\beta$-galactosidase activities. The results are means of three determinations. 
enzyme activity was monitored for three cultures of strain JA140, grown on (i) L-rhamnose, (ii) L-rhamnose plus Dglucose, or (iii) L-rhamnose plus D-glucose plus $5 \mathrm{mM}$ cAMP, showed how glucose repression, indicated by very low $\beta$-galactosidase activities, was partially abolished by the presence of cAMP (Fig. 5).

L-Rhamnose is metabolized aerobically as well as anaerobically in E. coli (Boronat \& Aguilar, 1979). Activities of the enzymes of the rhamnose pathway, such as rhamnose isomerase, were always found to be two to three times higher in anaerobic than in aerobic conditions (not shown). The $\beta$-galactosidase reporter activity also showed that the presence or absence of oxygen affects the expression of $r b a T: \beta$-galactosidase activities were again between two and three times higher for the cells grown under anaerobic conditions (Table 2).

\section{Analysis of deletions into the rhat promoter}

To identify the sequences important for $r b a T$ promoter function, deletions upstream of the transcriptional start site were generated. A partial deletion of fragment 1 (position -144 to +383$)$ generated fragment $2(-93$ to +383 ) with a $5^{\prime}$ end-point 50 bp shorter (see Fig. 1). Fragments $3(-67$ to +90$)$ and $4(-28$ to +338$)$ were generated from fragment 1 by digestion with $B s r \mathrm{I}$ and TaqI, respectively, and they had $5^{\prime}$ end-points that were 77 and $116 \mathrm{bp}$ shorter. The deletions were cloned into pRS550 and then recombined onto the chromosome as single copies as indicated above. Growth on casein acid hydrolysate in the presence of L-rhamnose of strains JA142 and JA143, containing the fusions of fragments 3 and 4 respectively, gave no $\beta$-galactosidase activity, indicating that these deletions essentially abolished transcription (Fig. 1). Neither L-lyxose nor L-mannose was able to activate the $\beta$-galactosidase activity in these strains (not shown). Growth of strain JA141, containing the fusion of fragment 2, on L-rhamnose, L-lyxose or Lmannose yielded intermediate levels of activity (Table 2), whereas growth of strain JA140 with the complete rbaT promoter in the same conditions displayed, as indicated above, full induction with higher levels of $\beta$-galactosidase activity.

\section{Role of RhaR and RhaS in rhaT expression}

To determine whether $r b a T$ was also under the regulatory cascade mediated by $r b a \mathrm{R}$ and $r b a S$ described by Egan \& Schleif for $r b a B$ (Egan \& Schleif, 1993), we complemented strains having deletions in the $r b a$ genes with plasmids pJTC105, pJTC108 and pJTC114, containing rbaSR, rbaS or $r b a \mathrm{R}$ respectively. In these plasmids the cloned genes were expressed from the tac promoter present in the vector (Tobin \& Schleif, 1990b). Experiments were run in parallel with the corresponding vector pTAC12 as control.

The $p c n B$ strain JA147, carrying the deletion $\Delta(r b a S R) 15$ of strain DF903 (Daldal \& Fraenkel, 1981) and the fusion of lac $Z$ with the rbaT promoter, was used in the complementation experiments. Hybridization of a Southern blot of strain DF903 DNA with several probes of $r b a$ genes indicated that the deletion starting at $p f k A$ ended between $r b a A$ and $r b a D$ and consequently deleted both $r b a S$ and $r b a R$. Complementation was revealed by the $\beta$-galactosidase activity produced by the $r b a T-l a c Z$ fusion present in strain JA147. The $p c n B$ background was used to avoid plasmid toxicity effects.

As a control, complementation experiments were run in parallel with strain JA148, carrying the $r b a-p f k A$ deletion and the fusion with the promoter of rbaB $A D$. Strain JA148 was constructed by initially introducing the $r b a B$ promoter fusion (Moraljo et al., 1993) into TE2680 (forming JA144) and the fusion was subsequently transduced into JA145 by P1 transduction.

Strain JA147 was induced by L-rhamnose, as indicated by the levels of $\beta$-galactosidase detected (Table 3), when transformed with pJTC105 (rbaSR) or pJTC108 (rhaS), which overexpress the RhaS regulatory protein (Tobin \& Schleif, 1990a). Complementation with pJTC114 (rbaR) showed no induction, as the overexpression of RhaR regulatory protein had no rbaS gene to activate. These results were absolutely paralleled by those obtained with strain JA148 containing the $r b a B$ fusion (Table 3).

The function of $r b a \mathrm{R}$ in the cascade model (Egan \& Schleif, 1993) for the expression of rbaT was ascertained by using a strain deleted in rbaR but not in rbaS (strain $\triangle$ RHA2). As for strain DF903, the extent of the deletion was determined. Hybridization of Southern blots of DNA from the deleted strain with internal probes of the regulatory region showed that the deletion started upstream of $r b a T$ and ended in $r b a R$, thus affecting $r b a R$ but not rbaS (data not shown). This time, fusions of the rbaT promoter and the rhaB promoter were incorporated into pcnB strain JA146, which is isogenic with strain JA145, giving rise to strains JA149 and JA160, respectively (JA145 and JA146 were constructed by P1 transduction of the $g l p^{+}$locus from $\triangle$ RHA2 into GD246).

Strain JA149 was inducible by rhamnose not only when transformed with pJTC105 or pJTC108 but also when transformed with pJTC114, which complemented rbaR in a strain lacking rbaR but having rbaS encoded in the chromosome (Table 3). The level of expression of the genomic rbaS caused a level of $\beta$-galactosidase lower than that obtained with the high expression of the plasmidencoded rbaS. Consistently, transformation with the vector gave no induction since the genomic rbaS lacked the required $r b a R$ product for its expression. These results were again paralleled by those obtained with control strain JA160 (Table 3).

The dependence of the expression of rbaT on rbaSR function was also confirmed by measuring the rhamnose uptake in the $r b a C$-deficient mutant strain CGSC4833 when transformed with the corresponding plasmids. The transformed cells restored the incorporation of radioactive rhamnose at concentrations that would not permit entry of the sugar in the absence of thamnose permease, indicating the presence of the transport system under 
Table 3. Complementation of rhaS-rhaR to express rhaT or rhaBAD in strains deleted of rha genes

\begin{tabular}{|c|c|c|c|c|c|c|}
\hline \multirow[t]{2}{*}{ Strain } & \multirow[t]{2}{*}{$\begin{array}{c}\text { Relevant rha genotype } \\
\text { in host }\end{array}$} & \multirow[t]{2}{*}{$\begin{array}{l}\text { Carbon } \\
\text { source* }\end{array}$} & \multicolumn{4}{|c|}{$\begin{array}{c}\beta \text {-Galactosidase activity in cells } \\
\text { bearing plasmid } \dagger\end{array}$} \\
\hline & & & $\begin{array}{l}\text { pJTC105 } \\
\text { (rhaSR) }\end{array}$ & $\begin{array}{l}\text { pJT108 } \\
\text { (rhas) }\end{array}$ & $\begin{array}{l}\text { pJTC114 } \\
(\text { rhaR })\end{array}$ & $\begin{array}{l}\text { pTAC12 } \\
\text { (vector) }\end{array}$ \\
\hline \multirow{2}{*}{ JA147 } & $\Delta r b a S R / \Phi(r b a T-l a c Z)$ & L-Rhamnose & 2490 & 2360 & $<25$ & $<25$ \\
\hline & & $\mathrm{CAH}$ & 105 & 160 & $<25$ & $<25$ \\
\hline \multirow[t]{2}{*}{ JA148 } & $\Delta r b a S R / \Phi(r b a B-l a c Z)$ & L-Rhamnose & 3780 & 5815 & $<25$ & $<25$ \\
\hline & & $\mathrm{CAH}$ & 210 & 105 & $<25$ & $<25$ \\
\hline \multirow[t]{2}{*}{ JA149 } & $\Delta r b a \mathrm{R} / \Phi(r b a T-l a c Z)$ & L-Rhamnose & 2550 & 3930 & 1575 & $<25$ \\
\hline & & $\mathrm{CAH}$ & $<25$ & $<25$ & $<25$ & $<25$ \\
\hline \multirow[t]{2}{*}{ JA160 } & $\Delta r b a \mathrm{R} / \Phi(r b a B-l a c Z)$ & L-Rhamnose & 5005 & 6660 & 1895 & $<25$ \\
\hline & & $\mathrm{CAH}$ & $<25$ & $<25$ & $<25$ & $<25$ \\
\hline
\end{tabular}

* $\mathrm{CAH}$, casein acid hydrolysate.

$\dagger$ Expressed as $\mathrm{nmol} \mathrm{min}^{-1}$ (mg protein $)^{-1}$.

Table 4. L-Rhamnose isomerase and L-rhamnose permease activities in strain CGSC4883 transformed with different plasmids

\begin{tabular}{|c|c|c|c|}
\hline \multirow[t]{2}{*}{ Plasmid } & \multirow{2}{*}{$\begin{array}{l}\text { L-Rhamnose } \\
\text { in growth } \\
\text { medium }\end{array}$} & \multicolumn{2}{|c|}{ Specific activity } \\
\hline & & Isomerase* & Permease $\nmid$ \\
\hline \multirow[t]{2}{*}{ pJTC105 (rbaSR) } & + & 390 & $4 \cdot 5$ \\
\hline & - & 60 & $<0.1$ \\
\hline \multirow[t]{2}{*}{ pJTC108 (rbas) } & + & 425 & $4 \cdot 2$ \\
\hline & - & 55 & $<0 \cdot 1$ \\
\hline \multirow[t]{2}{*}{ pJTC114 (rbaR) } & + & 450 & $4 \cdot 0$ \\
\hline & - & 32 & $<0 \cdot 1$ \\
\hline \multirow[t]{2}{*}{ pTAC12 (vector) } & + & 30 & $<0.1$ \\
\hline & - & 45 & $<0.1$ \\
\hline
\end{tabular}

* Expressed as milliunits ( $\mathrm{mg}$ protein) ${ }^{-1}$ at $37^{\circ} \mathrm{C}$.

† Expressed as nmol min ${ }^{-1}$ per $10^{9}$ cells at $30^{\circ} \mathrm{C}$.

inducing conditions (Table 4). As expected, uptake was hardly detectable in the untransformed cells of strain CGSC4833 (data not shown). Likewise, when one of the activities of the rbaB $A D$ operon, such as rhamnose isomerase, was determined, it was clearly seen that each of the three plasmids was restoring the activity which was absent in the mutant cell while the vector was unable to restore it even in the presence of rhamnose (Table 4). This result matched those obtained with strain JA149, which allowed us to locate the mutation in strain CGSC4833 in $r b a R$.

\section{DISCUSSION}

The determination of the transcriptional start site has allowed us to locate the putative elements of the rbaT promoter and subsequently to make the constructions to analyse the regulation of its expression. In this way we may identify, utilizing the sequence determined by GarcíaMartín et al. (1992), putative -10 and -35 boxes, an inverted repeat likely to interact with RhaS and a CRP consensus inverted repeat (see Fig. 4a). The fusions with the deleted $r b a T$ promoter indeed indicate the presence of two control elements. One of these, distal to tsp, is responsible for the sensitivity to catabolite repression as indicated by the reduced level of expression of strain JA141, which lacks part of the enhancing CRP element. Partial induction by rhamnose in this fusion indicated that the other control element, proximal to tsp, is still present in the remaining promoter sequences. This specific element is sensitive to induction by $\mathrm{L}$-rhamnose as indicated by the loss of expression shown by strain JA142, which has a $5^{\prime}$ deletion to the -67 position (Figs 1 and 4a).

Some similarities may be pointed out between this promoter and the $r b a B A D$ promoter described by Egan 
\& Schleif (1993). On the one hand, the location of these two putative control elements from tsp in the rbaT promoter is the same as that described for the control elements of $r b a B A D$ (Fig. 4b). On the other hand, there is high similarity between the putative CRP element in $r b a T$ and the identified CRP element in rhaB $A D$ ( 9 out of $10 \mathrm{bp}$ match), and also with the core consensus for CRP protein binding (again 9 out of $10 \mathrm{bp}$ match) (de Crombrugghe $e t$ al., 1984). With respect to the other inverted repeat potentially acting as RhaS binding site in $r b a T$, a significant base-pair matching is also found with that of $r b a B A D$. It has to be pointed out that in $r b a B A D$ promoter this inverted repeat has been experimentally proved to be recognized by RhaS (Egan \& Schleif, 1994).

Both regulatory proteins, RhaR and $\mathrm{RhaS}$, recognize and bind L-rhamnose, becoming in this way activated to induce the corresponding elements of the rhamnose regulon. Induction of the rhamnose system by sugars such as L-lyxose or L-mannose indicates that, due to structural similarity these sugars are also recognized by the two regulatory proteins. However, other structurally related sugars such as L-fucose, $\mathrm{D}$-arabinose or L-galactose, which have a different stereoconfiguration in the hydroxyls at carbons 2 and 4, are not recognized.

The regulation of $r b a B A D$ expression was shown to respond to a cascade in which $\mathrm{RhaR}$ induced rhaSR expression, and $\mathrm{RhaS}$ in turn induced rbaB $A D$. Our experiments involving complementation of $r b a S$ and $r b a R$ with plasmids bearing the regulators show that $\mathrm{RhaS}$ also acts as a direct regulator of $r b a T$ in the absence of $r b a R$, and that RhaR must be supplied for RhaS synthesis and accumulation in a strain in which $r b a R$ has been deleted. Thus the regulatory cascade proposed for the induction of $r b a B A D$ is also functional for the stimulation of the $r b a T$ promoter. In our experiments, a control fusion with the $r h a B A D$ promoter was always run in parallel to validate the comparison.

\section{ACKNOWLEDGEMENTS}

We thank S. M. Egan and R. F. Schleif for kindly providing the plasmids and R. Rycroft for editorial assistance. This work was supported by grant PB94-0829 from the DGICYT, Spain.

\section{REFERENCES}

Badia, J., Baldomà, L., Aguilar, J. \& Boronat, A. (1989). Identification of the $r h a A, r b a B$ and $r b a D$ gene products from Escherichia coli K12. FEMS Microbiol Lett 65, 253-258.

Badia, J., Gimenez, R., Baldomà, L., Barnés, E., Fessner, W-D. \& Aguilar, J. (1991). L-Lyxose metabolism employs the L-rhamnose pathway in mutant cells of Eschericbia coli adapted to grow on Llyxose. J Bacteriol 173, 5144-5150.

Baldomà, L., Badfa, J., Sweet, G. \& Aguilar, J. (1990). Cloning, mapping and gene product identification of rbaT from Escherichia coli K12. FEMS Microbiol Lett 72, 103-108.

Belasco, J. G., Beatty, T., Adams, C. W., von Gabain, A. \& Cohen, S. N. (1985). Differential expression of photosynthesis genes in $R$. capsulata results from segmental differences in stability within the polycistronic $r \times c A$ transcript. Cell 40, 171-181.

Boronat, A. \& Aguilar, J. (1979). Rhamnose-induced propanediol oxidoreductase in Escherichia coli: purification, properties, and comparison with the fucose-induced enzyme. I Bacteriol 140, 320-326.

Chen, Y.-M., Tobin, J. F., Zhu, Y., Schleif, R. F. \& Lin, E. C. C. (1987). Cross-induction of the L-fucose system by L-rhamnose in Escherichia coli. J Bacteriol 169, 3712-3719.

de Crombrugghe, B., Busby, S. \& Buc, H. (1984). Cyclic AMP receptor protein: role in transcription activation. Science 224 , 831-838.

Daldal, F. \& Fraenkel, D. G. (1981). $\operatorname{Tn} 10$ insertions in the $p f k B$ region of Eschericbia coli. J Bacteriol 147, 935-943.

Dische, Z. \& Borenfreund, E. (1951). A new spectrophotometric method for the detection and determination of keto sugars and trioses. J Biol Chem 192, 583-587.

Egan, S. M. \& Schleif, R. F. (1993). A regulatory cascade in the induction of $r b a B A D$. J Mol Biol 234, 87-98.

Egan, S. M. \& Schleif, R. F. (1994). DNA-dependent renaturation of an insoluble DNA binding protein. Identification of the RhaS binding site at rbaBAD. J Mol Biol 243, 821-829.

Elliott, T. (1992). A method for constructing a single-copy lacI fusions in Salmonella typhimurium and its application to the bem A-prf $A$ operon. J Bacteriol 174, 245-253.

Garcla-Martin, C., Baldomá, L., Badía, J. \& Aguilar, J. (1992). Nucleotide sequence of the $r b a R-s o d A$ interval specifying $r b a T$ in Eschericbia coli. J Gen Microbiol 138, 1109-1116.

Hacking, A. J. \& Lin, E. C. C. (1976). Disruption of the fucose pathway as a consequence of genetic adaptation to propanediol as a carbon source in Escherichia coli. J Bacteriol 126, 1166-1172.

Holmes, D. S. \& Quigley, M. (1981). A rapid boiling method for the preparation of bacterial plasmids. Anal Biochem 114, 193-197.

Hu, C. T. \& Davidson, N. (1986). Mapping transcriptional start points on cloned genomic DNA with T4 DNA polymerase: a precise and convenient technique. Gene 42, 21-29.

Lin, E. C. C. (1976). Glycerol dissimilation and its regulation in bacteria. Annu Rev Microbiol 30, 535-578.

Miller, J. H. (1972). Experiments in Molecular Genetics. Cold Spring Harbor, NY: Cold Spring Harbor Laboratory.

Moralejo, P., Egan, S. M., Hidalgo, E. \& Aguilar, J. (1993). Sequencing and characterization of a gene cluster encoding the enzymes for L-rhamnose metabolism in Escherichia coli. $J$ Bacteriol 175, 5585-5594.

Power, J. (1967). The L-rhamnose genetic system in Escherichia coli K12. Genetics 55, 557-568.

Sambrook, J., Fritsch, E. F. \& Maniatis, T. (1989). Molecular Cloning: a Laboratory Manual. Cold Spring Harbor, NY: Cold Spring Harbor Laboratory.

Sanger, F., Nicklen, S. \& Coulson, A. R. (1977). DNA sequencing with chain terminating inhibitors. Proc Natl Acad Sci USA 174, 5463-5467.

Simons, R. W., Houman, F. \& Kleckner, N. (1987). Improved single and multicopy lac-based cloning vectors for protein and operon fusions. Gene 53, 85-96.

Sweet, G., Gandor, Ch., Voegele, R., Wittekind, N., Beuerle, J., Truniger, V., Lin, E. C. C. \& Boos, W. (1990). Glycerol facilitator of Escherichia coli: cloning of $g l p F$ and identification of the $g l p F$ product. J Bacteriol 172, 424-430.

Takagi, Y. \& Sawada, H. (1964). The metabolism of L-rhamnose in Eschericbia coli. I. L-Rhamnose isomerase. Biochim Biopbys Acta 92, 10-17.

Tate, C. G., Muiry, J. A. R. \& Henderson, P. J. F. (1992). Mapping, cloning, expression and sequencing of the $r b a T$ gene, which 
encodes a novel L-rhamnose- $\mathrm{H}^{+}$transport protein in Salmonella typhimurium and Escherichia coli. J Biol Chem 267, 6923-6932.

Tobin, J. F. \& Schleif, R. F. (1987). Positive regulation of the Escherichia coli L-rhamnose operon is mediated by the products of tandemly repeated regulatory genes. J Mol Biol 196, 789-799.

Tobin, J. F. \& Schleif, R. F. (1990a). Transcription from the $r$ a operon $\mathrm{p}_{\mathrm{SR}}$ promoter. $J$ Mol Biol 211, 1-4.
Tobin, J. F. \& Schleif, R. F. (1990b). Purification and properties of RhaR, the positive regulator of the L-rhamnose operons of Eschericbia coli. J Mol Biol 211, 75-89.

Received 27 October 1995; revised 19 January 1996; accepted 5 February 1996. 